Meta

Journal des traducteurs

Translators' Journal

\title{
Interpreting for International Satellite Television
}

\section{A. Daly}

Volume 30, numéro 1, mars 1985

Interprétation de conférence

URI : https://id.erudit.org/iderudit/002445ar

DOI : https://doi.org/10.7202/002445ar

Aller au sommaire du numéro

Éditeur(s)

Les Presses de l'Université de Montréal

ISSN

0026-0452 (imprimé)

1492-1421 (numérique)

Découvrir la revue

Citer cet article

Daly, A. (1985). Interpreting for International Satellite Television. Meta, 30(1),

91-96. https://doi.org/10.7202/002445ar d'utilisation que vous pouvez consulter en ligne.

https://apropos.erudit.org/fr/usagers/politique-dutilisation/ 


\section{INTERPRETING FOR INTERNATIONAL SATELLITE TELEVISION}

A. DALY

\section{INTRODUCTORY NOTE}

Any programme intended for European-wide broadcasting must, if it is to appeal to more than a highly marginal audience, overcome the problem of cultural diversity commonly known as the "language barrier". This implies a huge task of translation and adaptation and what has been called in a recent article a "language factory". The task requires specialized techniques and highly specialized people who can reliably span the cultures and languages to be transposed while having the necessary experience of the broadcasting medium. These exist in the form of translators, dubbers, voice-over artists, subtitlers and the processing in "live" programmes, the additional specialisation of experienced conference interpreters.

If broadcasting were to go on as at present within national frontiers that would be the end of the story and we should in all likelihood see the above techniques and specialists continuing to be used in much the same way as now, and in much the same proportions, to handle the occasional foreign programme.

The unique contribution of the Eurikon experiments described below was to show that in a situation of hugely expanded demand, (and no doubt contracted lead-times), there might have to be not only many more of the above specialists but perhaps also a more extensive panoply of techniques more finely tunable to the producer's requirements and more capable of responding to the general needs or programming.

\section{EURIKON AND THE LANGUAGE PROBLEM}

Eurikon was the name given to a series of broadcasting experiments held in 1982 to test the potential appeal of a European Programme. The OTS (Orbital Test Satellite) was used to beam close to 200 hours of television to fifteen countries, where broadcasting executives and panels of opinion-leaders were invited to assess them at specially equipped viewing centres.

The Programme went out from five production centres (London, Rome, Vienna, Hilversum, and Baden-Baden) in the course of five separate weeks between May and November.

The experiments had certain inherent defects : rather than the programmes being specifically designed and produced for a European-wide audience, considerations of time and money limited the choice to existing schedules; they also led to an entirely ad hoc solution to what we shall call the "language transfer problem", namely : simultaneous interpretation.

Few specialists, if asked, would suggest using this method to cover (as was the case) a full mix of programmes from feature films to sporting events and back by way of Shakespeare and fast comic patter from a cabaret! 
They would no doubt advocate the traditional methods of dubbing and subtitling, with voice-over from a translated script for such things as recorded interviews, etc.

Simultaneous interpretation would be something of a last resort, to be used only for live unscripted material, in line with current practice in most broadcasting organisations.

However, for the reason given, it was not possible to deal with the problem in the "normal" way. The only method available to give meaning to the experiment and allow it to achieve its purpose was to use conference interpreters. The experience of some members of the operations group with the use of interpreting at certain marts and festivals probably accounts for its being used at all. On those occasions the purpose is not so much to produce the emotional and intellectual impact of a programme through the interpretation, but to convey an idea of its spoken content. This method has worked perfectly satisfactorily for many years at such events as the Prix Italia and it was felt it could serve equally well in what were seen to be comparable circumstances. It is necessary to know this piece of background in order to understand some of the otherwise contradictory conclusions that came out of the experiment.

\section{THE TESTS}

The Satellite TV link offered the possibility of six sound channels. The requirement was therefore to produce an instantaneous translation of a broadcast in any one of six languages (English, French, German, Italian, Dutch, Spanish) into all the others as it left the production studio to go over the air. Interpreting booths were set out in a large room or studio with television monitors in front of each one, placed at a distance of about $150 \mathrm{cms}$ and somewhat below eye-height.

Teams of three interpreters were used in the initial tests, since, although the programme lasted only five hours and there were considerable periods of rest (a one hour and forty minute opera for example), it ran late in the evening (6 p.m. - 11 p.m. or 7 p.m. - 12 p.m.) and it was impossible to know how great the strain would be. Towards the end team strength was selectively reduced, partly to allow for the use of professional announcers.

Another reason why it was initially thought desirable to have larger teams was to be able to have greater variety of voice and especially to be able to cover a female voice by a woman interpreter and a male voice by a man. This proved impossible, largely through recruitment difficulties, but also because of the unequal division of work which would have resulted. The principle was finally applied selectively (type of programme, type of speech), but it is part of a much more general problem of voice matching to which we shall return later.

During the preparations, it was made clear that all programme scripts should be made available to the interpreters as far as possible in advance and that facilities should exist to allow pre-viewing of all programmes. That these requirements were only partially met was an additional difficulty, especially with the news, of which more later.

Another much more unexpected source of difficulty was the equipment provided for the interpreters. Clear instructions had been given that this should be to normal specifications (a copy of ISO Standard was supplied) and should permit relay from all booths. This latter requirement was in fact only met during one test. At all the others we had to resort to every kind of ingenious contrivance to get relay out of one booth*.

There were, however, other problems : firstly that of unfamiliarity. In spite of repeated pleas for standard equipment in every case, again no doubt for financial reasons, the headset and control boxes were imperfectly adapted commentary units : the headsets were heavy and covered a large area of face and head ; the panels contained a bewildering array of knobs and switches, which were only successfully dealt with, late on in 
the series, by covering most of them with adhesive tape. Moreover, the interpreters found it disconcerting in the extreme not to be able to switch their own microphone on and off. Most alarming of all, however, was the experience of the first test at which we had two different sound sources, one fed to each earphone, the first being normal programme sound, the second being the production unit in the control room where people stood around emitting an endless stream of chatter. This is apparently normal practice for newsreaders and sports commentators.

The interpreters showed remarkable flexibility in adjusting to these many unfamiliar features, even coping on one occasion with a quickly improvised sign language with which to communicate with control engineers handling their microphones immediately in front of the booths.

In the first two tests, interpreting was used on virtually every programme containing speech. On the third test, it was used more selectively and alternated with an introduction in the various languages given during the credit titles, the actual programme being transmitted in the original language.

In the fourth test, organised by the Dutch organisation, interpreting was dispensed with altogether in favour of traditional methods. This required a much greater locally produced effort to get in the programmes, translate and dub or sub-title them. The Dutch have considerable experience of this and can call on a large pool of in-house or free-lance translators and/or bi-lingual journalists. This was generally perceived as much more acceptable in terms of language transfer and in the fifth and last test it was felt desirable that there should be an attempt to combine the two methods : interpretation and translation with professional voice-over. It was thought that the material could be divided in such a way as to apply the more suitable treatment to each programme while permitting an overall comparison and assessment of the methods. This was to prove impossible in any systematic way, again largely due to recruiting difficulties, but the presence of separate teams using different methods threw up some interesting problems and allowed some useful conclusions to be drawn.

\section{THE RESULTS - TELEVISION}

The results were positive in that the test panels (and" subsequently a much wider body of opinion) found the programme interesting and worthwhile. They stated that, given the choice, they would watch it in addition to their national programmes.

A television company is being set up by the broadcasting organisations involved in the experiment to provide a European programme to a large part of Europe and North Africa. It is to start operations next year in six languages from studios in Holland. The intention is that it should deal mainly in news, information and comment from a European viewpoint.

The experiment also served to focus the interest of the Community Institutions, especially the European Parliament, which has recently adopted a number of resolutions pledging support for a Pan-European Multilingual programme, preferably one providing enlightened comment for professional and business circles and helping to create a European consciousness or viewpoint.

It had long been felt in the Community that the lack of such a viewpoint accounts for the warm indifference, not to say apathy, displayed by the public in the various member states for most matters European. The lukewarmness of the campaigns and the disappointing turnouts at the recent elections to Parliament will have done nothing to dispel this feeling. Hence the readiness to promote a TV channel dedicated to filling the vacuum. 
The signs are therefore, that as from 1988 or so, there will be full-scale European broadcasting to the public on the "Reithian" principles of "to inform, educate and entertain", although possibly with the emphasis on the first two at the expense of the third.

\section{THE RESULTS - LANGUAGE TRANSFER}

Here the conclusion is more mixed. As one would expect, the panellists and TV executives found that traditional methods $i$.e. dubbing, subtitling and voice-over were to be preferred to simultaneous interpretation. It might be remarked at this stage by anyone knowledgeable that you really didn't need to do 200 hours of broadcasting over a satellite to discover that ! Indeed, they might add, that question should never have been asked. The interpreters were only there "faute de mieux", so to speak. What is more, while the language transfer problem would never be tackled by grafting on a set of illprepared interpreting links at the end of the chain, it can also safely be assumed that no self-respecting European programme would ever be produced from the national schedules of the participating broadcasting organisations.

In other words, the experimental set-up was no guide to the real problem. It was, in a sense, a mistake. But a very fruitful one for anybody interested in examining the constraints of international television.

Not the least of these is the lack of understanding of the interpreting process which is to be found even among quite sophisticated users. For example on several occasions we were asked to summarize the commentary on a programme which we were hearing for the first time! Another remarkable example was of a programme which lent itself very well to interpreting, but where the producer had cut out large parts of the script given to the interpreters so that, speaking rather more slowly, their translation would finish at the same time as the original. No one bothered to tell the interpreters of this plan. It was merely assumed that they would read out the script provided, paying no attention to what they were hearing and pacing themselves by some internal clock !

\section{THE REAL PROBLEM}

At a very early stage (immediately after the first test in London) I said in a report that to be successful, interpreters should be moved upstream and more closely integrated into the production process. I had in mind of course, a broad spectrum of linguists and linguistic activities - translators, journalists with several languages, interpreters - translating scripts, adapting commentaries, summarizing hot items for editors in the newsroom, and so on.

It seemed to me that, in the course of production it would be fairly obvious who did what, and how. One great lesson to have come out of this experience for me is that this question is by no means clear. Not just because translators and interpreters - not to speak of journalists regard themselves as different species with superior expertise that needs no help from the others - we had proof of this with the mixed teams in the fifth week, each one doing their best to take over, making intelligent cooperation virtually impossible well before the end - and there was further proof more recently from a company producing news in London for continental TV's relying for language transfer entirely on machine translations re-shaped by journalists using their own native tongues. There is no doubt that much will have to be done to define - or re-define the boundaries between professional activities when the medium is internationalized.

There is, however, a much more important reason why it is not clear. It is that so soon as a voice is linked to a face the two have to be convincingly matched. For the sake of convenience we shall refer to this as the authenticity problem.

When, say, a film is dubbed, the chief need is to achieve lip synchronisation. If this can be maintained, especially for distinctive movements such as those accompanying 
plosives, then the illusion can be created that the face we are looking at is actually emitting the sounds we hear. A general lack of lip-sync will fail to generate this illusion and the viewer will feel cut off from the reality of the action. The importance of this synchronisation is so paramount that it is customary to depart from the strict sense of the dialogue in the translation, if necessary, in order to preserve it. This is not the only requirement to achieve authenticity, of course.

The voice must also match the person : man, woman, child, old, young, etc. It must also be cut into the ambient sound and not be identified as a separate source. These techniques are well-known and mastered, especially in countries where a great deal of dubbing is used. In Italy, for example, even original Italian dialogue is often postsynchronised - with no loss of authenticity. Even when done to perfection, however, some audiences reject dubbing. They find it impossible to accept a couple of Frenchmen talking in a Paris café in standard English. Attempts have been made to re-establish authenticity by the use of foreign accents with some success, but audiences in Scandinavia, the Netherlands and certain other countries prefer sub-titles. In other words, they accept a loss of information in order to preserve the "reality" of objects and events to which they are asked to relate emotionally. So strong indeed is the antipathy to dubbing in these countries that they even insist on sub-titles for current affairs or documentaries, thus sacrificing half the information.

It goes without saying therefore, that a perfect interpretation superimposed on the still audible sound-track of a feature film or drama with a perceptible lack of synchronisation will be completely rejected by the average TV audience. The rejection would be just as total if it were a written translation "voiced-over" in the same way.

This "authenticity" constraint is much less great of course, when the chief interest of an on-screen message is the information content. A "voice-over" translation of a statement by some visiting minister or dignitary does not attempt to create the illusion that it is the original sound, indeed that sound is often maintained at a level such that it can also be followed. The "voice-over" is thus presented and perceived as a sort of oral sub-title. It is a nuisance, inasmuch as it interferes with and detracts from the pristine event, but is accepted for the sake of information.

Clairly, interpretation can be used with the same results in these circumstances. Some observers during the tests in fact preferred it to "voice-over" as being more immediate and less artificial. It seems to be more readily perceived as co-existing with the event.

There is also a purely self-generated television "authenticity". People reading from a tele-prompter, for example, while pacing their speech to coincide with certain pictures, develop a peculiar but highly typical style of speaking, so that interpreters, who have their own, very different intonations, are rejected as unconvincing even when they are reading a script translated by themselves.

No doubt, much can be done through training, to master the various registers in use and thus acquire what passes for a television "sound".

Together with these problems, there are certain others which require technical solutions. Voice-over techniques, as has been said, maintain the original sound at reduced volume, thus creating a mix of languages at different levels. The setting of these levels appears to be highly critical. It was the subject of much complaint on the part of the viewing panels and can only be acceptably dealt with if the individual has a knob on his set with which to adjust the differential between the two sounds to a level he finds comfortable. It should also be possible to switch off entirely the original sound. Progress will probably also be needed to re-synthesize the timbre of the added voice to achieve more 
variety and better match, since it also detracts from authenticity to recognize a voice as being constantly used with different faces.

I have laboured the problem of the "talking head" at such length because it is customary, failing careful analysis, to extend its constraints to the medium as a whole and to limit the role of interpreting in TV as a result to those cases, listed above, where it is impossible to use any other method. In fact, in all programmes using "off-screen" commentary, interpretation can be employed as an alternative to translation and "voiceover". The choice will be a matter for the producer, naturally, but the advantages of interpreting spontaneity (even after minimum rehearsal), mimicry, liveliness - were very clearly demonstrated in the course of the experiments. I leave aside such practical considerations as cost, time available and others, which will also obviously influence the choice.

What is needed now is a readiness on the part of programme makers to experiment in this much more specific and selective context with conference interpreters, considering them not as a stop-gap or a rough-and-ready way of doing something which would more properly be done by other methods, but as an additional instrument capable of blending with the others, but also contributing its own authentic sound.

These remarks are of course based on television as it exists today, one prominent feature of which is the high content of scripted and rehearsed programmes. It may well be that in an environment of $30 \mathrm{TV}$ channels, we shall see development similar to what has happened in Radio, especially local radio, towards greater improvisation and spontaneity. Clearly such a development would open up far greater opportunities for the use of interpreters.

I should like to take this opportunity to place on record my gratitude to all the interpreters who worked on these experiments. The conditions of work and the constraints of an unfamiliar medium made almost impossible demands on them, but they maintained their good humour and enthusiasm throughout and won the admiration of all concerned by their unshakeable professionalism.

* Relay is not recommended. It was used only for minority languages to avoid impossible recruitment problems. 